\title{
INTEGRATING VIRTUAL REALITY AND BIM FOR END-USER INVOLVEMENT IN BUILDING DESIGN: A CASE STUDY
}

\author{
Ekaterina Petrova $^{1}$, Mai Brink Rasmussen ${ }^{2}$, Rasmus Lund Jensen ${ }^{3}$, and Kjeld Svidt ${ }^{4}$
}

\begin{abstract}
The outcome of projects within Architecture, Engineering, and Construction is highly dependent on the quality of the collaboration between the involved actors. The end-users occupy the buildings on a daily basis, and therefore their involvement in the design process is essential to the output. However, traditional practices place the responsibility of decision-making mostly in the architects' hands. Virtual Reality technologies coupled with Building Information Modelling have the potential to improve the collaboration and data visualization in the building design.

This paper presents the findings from a case study on the integration of Building Information Modelling and Virtual Reality for user-centred participatory interior furnishing of a new university building. Besides a significant reduction in the time for generation of alternative proposals, the end results show an increased attachment of the employees to their future workplace and a high level of acceptance towards the technology. Finally, the authors present suggestions for further work, which could improve future design processes utilizing the Virtual Reality technology.
\end{abstract}

Keywords: Virtual Reality, Building Information Modelling, End-User Involvement, Interior Design, Participatory Design

\section{INTRODUCTION}

The use of models for representation of the real world has been an integrated part of Architecture, Engineering and Construction (AEC) for centuries. The projects are characterized by collaboration between multidisciplinary parties and are highly dependent on the quality of the communication between them. The latter is essential during the design stage, where the impact of the decisions taken is highest. Therefore, the technical setup must be able to reflect and support the diverse skill sets of the client, the consultancy and construction professionals, and the end-users.

Visualization and communication of the interior design intent is an essential part of the process and can be achieved in different ways. Usually, this has been done by the use of physical prototypes (cardboard models or 1:1 mock-ups), 3D computer renderings and walk-throughs. Considering that the end-users occupy the building on a daily basis, it is important to involve them actively in the design, so that they can provide a valuable experience-based input for the future environment (Svidt and Sørensen 2016).

1 PhD Student, Department of Civil Engineering, Aalborg University, Aalborg, Denmark, ep@civil.auu.dk

2 PhD Student, Department of Civil Engineering, Aalborg University, Aalborg, Denmark, mbr@civil.auu.dk

3 Associate Professor, Department of Civil Engineering, Aalborg University, Aalborg, Denmark, rlj@civil.aau.dk

4 Associate Professor, Department of Civil Engineering, Aalborg University, Aalborg, Denmark, ks@civil.aau.dk 
However, physical facility representation has limitations, takes a long time to set up and is costly. In addition, capturing requirements by questionnaires or interviews depends on interpretation and requires numerous iterations. In that relation, Building Information Models and Virtual Reality (VR) can greatly benefit the industry, in terms of providing the capacity to improve communication, data visualization, and decision-making.

\subsection{Background}

VR started in the 1950s with Morton Heilig's Sensorama (1962) and had its breakthrough in the late 1980s/ beginning of 1990s. However, the price of the computers and VR-related technology at that time was too high to be widely affordable. Since then it has matured significantly and started offering a broad range of possibilities for finding solutions to complex problems (Thabet et al. 2002).

Isdale (1993) argued that VR has different meanings to different actors. In the current context, the term refers to "an experience in which a person is surrounded by a computer generated 3D representation and is able to move around in the generated virtual world and see it from different angles, reach into it, grab it, and reshape it" (Mifflin 2001). Throughout the years, further related concepts have been defined, including Mixed Reality (MR) and Augmented Reality (AR). To ensure comprehensiveness, results including these have been included in the literature study, but the upcoming sections of the paper use the term VR as per the definition stated above.

\subsection{Related works}

From the perspective of the AEC industry, VR can be viewed as means for process optimization. Being integrated into the day-to-day activities, it can be used for analyses related to acoustics and daylight, assessment of design changes and potential conflicts, constructability reviews, better collaboration, etc. (Kim et al. 2013). Those benefits are the underlying reason for the great interest in the area of VR applications in the industry, and development of new methods to assist the processes associated with it.

In recent years, the focus has started to shift from designing for to designing with the users. Various methods for user involvement in the design process have been suggested (Kim et al. 2015), (Eriksson et al. 2014), (Christiansson et al. 2011), (Bullinger et al. 2010). Studies have also been conducted on the gamification of BIM and its potential for supporting integrated projects (Selin and Rossi 2016), (Aydin and Schnabel 2014).

Some of the latest research efforts comprise methods for architectural co-design in VR (Dorta, et al. 2016); use of game engines and VR technology in collaborative design (Hilfert and Koenig 2016), (Edwards et al. 2015); VR-based cloud BIM platform for integrated projects (Goulding et al. 2014); interaction with multi-user VR (Porkka et al. 2012); VR for architectural acoustics (Vorländer et al. 2015), just to name a few.

A growing body of literature has examined the use of Virtual, Augmented and Mixed Reality (VAMR) in architectural design in particular. Abdelhameed (2014) reported on the relationship between VR and creativity with regards to problem definition, concept development and form exploration. In their work, Schulze et al. (2014) and Angulo (2013) investigated the effect of VR on architectural spatial experiences and the use of immersive simulation for improved design. An increasing amount of studies have also explored the possibilities that the virtual environments give for architectural visualization and collaboration (Portman et al. 2015), (Hsu 2015), (Wang et al. 2014), (Liu et al. 2014).

Several researchers have studied VR as a primary medium for user involvement in the hospital design process (Svidt and Sørensen 2016), (Tutt and Harty 2013), (Wahlström et al. 2010). In other efforts, Heydarian et al. (2015) and Niu et al. (2015) draw the attention 
to utilizing immersive virtual environments (IVEs) for understanding the end-users' behaviour and preferences.

Efforts have also been concentrated on discovering new ways for application of the VAMR technology in the interior design domain (Tang et al. 2014), (Siltanen and Oksman 2013), (Han and Seo 2013), (Zhou and Guo 2013). Oksman et al. (2012) also underline and approach the need of ready-and-easy-to-use tools for user participation in co-creative design. Davies (2004) particularly draws attention to the use of VR for participatory design of work environments and argues that the success is largely dependent on the size of the group utilizing the technology.

However, despite evolving significantly, VR's recent development has primarily been driven by consumer initiatives and not by professional use. In AEC, the efforts are mostly concentrated on the technological development of new solutions and do not report on the actual usability, efficiency, and effect of the available technology on the collaborative and co-creative workflows and processes.

\subsection{Objective}

The use of VR in the interior design process is becoming more common, but is still mostly limited to client visualizations and walk-throughs. The objective of this study is to use and evaluate the opportunities that VR technology and architectural BIM models provide, in order to improve the process, while directly involving the end-users. That would shift the focus from the architect as the main responsible actor and increase the commitment of the end-users to the building, by providing an opportunity to experience, co-design, and ensure that their requirements are met.

Ultimately, the study aims for investigation of the effects of the actual implementation of the developed VR system in the design process. More specifically, the effort contributes with knowledge related to efficiency, technology acceptance, level of involvement, design proposal generation, as well as the related collaborative workflows. Such knowledge may be of value in future research related to the use of VR in the AEC industry, as well as development and implementation of new technological solutions.

The paper builds upon a previously developed prototype system for user involvement in hospital design, described by Svidt and Sørensen (2016). The findings are based on a case study, aiming to document the results of the application of that system, by using it for the furnishing of Aalborg University's Department of Civil Engineering in Denmark.

\section{Methodology}

\subsection{Experimental setup and procedure}

The idea behind the building is for all activities to be collocated. The building accommodates 150 employees and 450 students on an area of nearly $9000 \mathrm{~m}^{2}$. Approximately $4000 \mathrm{~m}^{2}$ of the latter belong to laboratories and the other $5000 \mathrm{~m}^{2}$ to offices, group rooms, auditoriums and shared spaces.

The end-user involvement was organized in the form of a 1.5-day participatory design workshop. The workshop did not include the laboratory spaces, so the precise area for participatory interior furnishing was $5431 \mathrm{~m}^{2}$. The participating end-users were 20 (two 

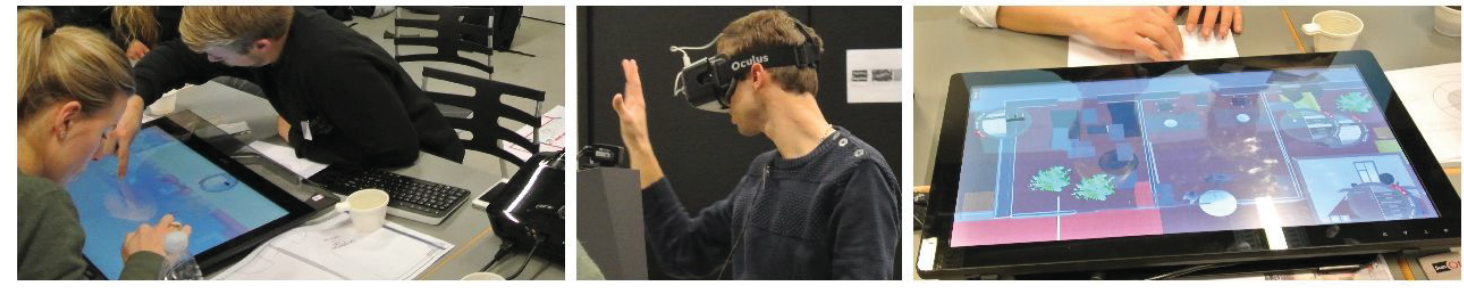

Figure 1: VR System and 2D Screen in simultaneous use

groups of 10), representing the management, employees, students and maintenance staff, as well as furniture providers and VR system developers.

According to Nicolini (2012), an object is transformed into an outcome with the help of an instrument, e.g. a tool or a language. In that relation, the used tools were divided into two groups: tools to support the task and tools to support the collaboration.

The tools to support the task include:

1. Floor plans, providing an understanding of the purpose, size and precise location of the room/space in the building.

2. A custom multi-user VR-system with computers, Oculus Rift head mounted displays and a touch screen, allowing to furnish the spaces in 2D plan view, while others are experiencing that real-time object arrangement in the 3D virtual environment (Figure 1). The system allowed both collocated and externally located users to take part, as well as seeing each other's avatars and pointing at different objects in VR. A customized Autodesk Revit to 3DSMax to Unity 3D workflow facilitated the use of the BIM models in VR.

3. The building model, the specific rooms to be furnished and the furniture objects.

4. Printer for the different interior arrangement proposals.

5. Excel sheet for the furniture unit costs and Dropbox access for saving print screens.

6. Projector for screening the 3D experience.

7. Scorecards for evaluation/comparison of the different interior design proposals.

While the tools mentioned above were there to support the task, several of them also supported the collaboration. For instance:

1. The plans, as they provided a common understanding of the building.

2. VR-system, because the experience facilitated relevant discussions.

3. Projector, because it provided a real-time experience for all actors and not only those who were experiencing it in VR at the moment.

\subsection{Data collection and analysis}

The following methods were used for data collection:

- Participant observation- the facilitator was observing and documenting the entire process with the help of Techno- Anthropology master students.

- Video- the entire workshop and the ongoing collaborative processes were recorded and referred to during the data analysis.

- Decision diagrams and evaluation notes were used to record the decision-making and the participant feedback.

- Interview- a representative of the university campus service with an experience with interior arrangement of similar buildings was interviewed. 
Cluster analysis and pattern-matching were then used to analyse the collected data and classify the results in different categories.

\section{RESULTS}

Generally, the results of the session can be divided into (1) Improvement of the interior design process with regards to efficiency, (2) Full involvement of the end-users in the decision-making, (3) Achieving a common understanding (4) Attachment to the future workplace and (5) Feeling of contribution to the interior design process, which traditionally would not include end-users to such an extent, and (6) Areas for further development. They are further elaborated on in the discussion section.

The teams produced design proposals for the entire area of $5431 \mathrm{~m}^{2}$ and nine types of rooms within 5.5 hours. For each type of room, they made ten proposals, which they evaluated by the use of the scorecard and then selected the three best ones (Figure 2). Finally, each room's future occupants agreed on a single solution.

Despite initially being intimidating, the VR technology marked a high acceptance rate. That is due to the high level of immersion and the photorealistic experience of the virtual environment. However, during the session, it was clear that the system needed adjustments and technical calibration. For instance, it became apparent that certain gamification principles such as resource use, direct communication within the virtual environment and saving of the current scenes were not implemented, but were desirable.

The price of each furniture unit and the maximum amount for each room were stated, and the actors had the opportunity to track the total amount used. Even though the responsibility for budget handling was given to a participant in the role of a secretary, who was handling all related tasks mostly manually, tracking of the economy made adhering to the total budget possible at the moment of decision-making. Traditionally, that requires numerous exchanges between the design team and the client.

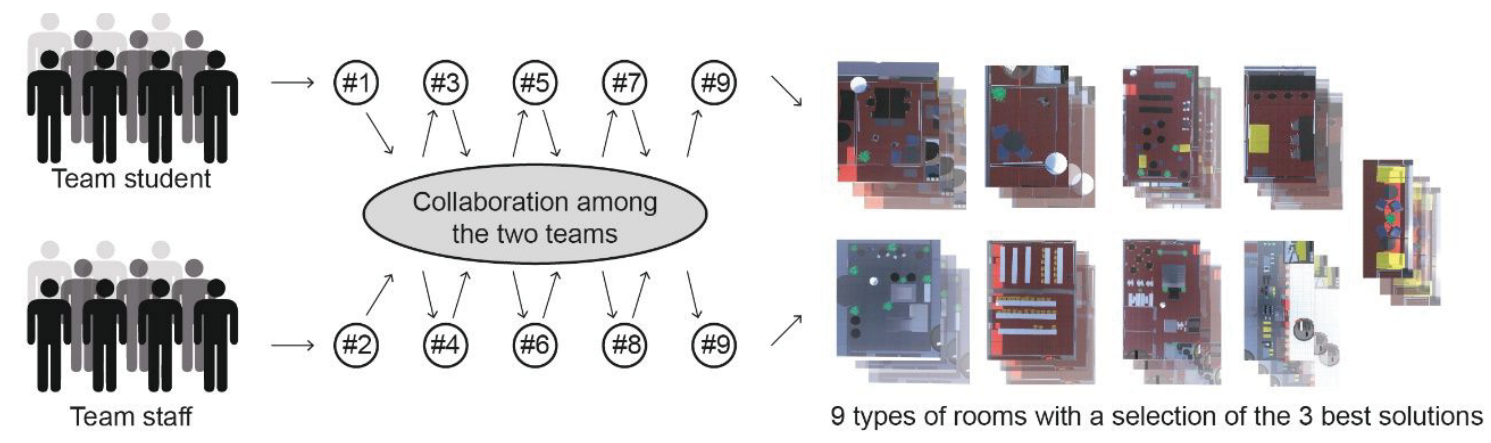

Figure 2: Participatory design workshop organization and output

\section{DISCUSSION}

One of the most important and intended outcomes of the experiment is the significant reduction of the time for the furnishing of the space. According to the university's campus service organization, similar processes executed in a traditional way have previously taken months. In this case, the task was completed within hours and in agreement. The interior arrangement was simultaneously influenced by multiple end-user perspectives, stemming from the participants' background and experience, e.g. research, study activities, teaching, administration, etc. Usually, the end-users are not a part of the actual decision- making 
during modelling, and that is why the majority of the actors were satisfied to be a part of the process. The provided feedback shows that the general expectations of the end-users were fulfilled. The participants referred to the process as revolutionary and long- awaited. They achieved an understanding of each other's interests, working methods, and expectations.

During the session, the vertical hierarchy transformed into a horizontal one, where all actors had equal opportunities for input, decision- making and experience reuse. Each user group was aware of their needs that equalized the level of expertise. The actors developed a feeling of joint ownership and therefore a closer relationship to the future building. The sense of ownership is usually developed after moving into the premises, but in this case, it was already present during the design stage, as the participants showed an increased interest and defended their design proposals.

The ability to see each other in VR and point at the objects by hand or with a laser pointer additionally contributed to the better understanding and collaboration between the actors, although it was not utilized to a high extent. The session also developed a shared vocabulary among the actors. Despite the different professional background, they managed to achieve a common understanding of the rooms and an acceptance of the VR system as an easy-to-use technological solution. That is particularly valuable, as it means that an optimized process is possible without skills, characteristic to only design professionals or tech-savvy users.

However, from a technological perspective it was discovered that to be able to provide optimal support, the system needs further development and expansion of the functionality. From an information management perspective the system provided the desired effect related to visualization and first person experience, but not being able to save scenes led to decision-making based on printed materials/screenshots. The latter, together with the identified need of a person to handle the budget showed that parts of the process were still closer to the traditional practices and did not utilize the full potential that VR and BIM have to offer. The required Revit to Unity 3D workflow also required time and effort, which can be avoided with a direct integration between the native BIM software and the VR technology. Therefore, the future work includes investigations into possibilities for process optimization, further development of the system and its re-utilization in new experiments of extended scope and scale. That includes finding new analytical areas where VR can have a significant value contribution.

\section{CONCLUSION}

The paper presented an evaluation of an integration of Virtual Reality Technology and Building Information Modelling for end-user involvement in interior design.

The results show that experiencing Building Information Models in a virtual environment holds a significant potential related to time for decision-making and level of collaboration. Also, a full involvement of the end-users was achieved, which lead to a common understanding between the actors, attachment to the future works place, joint contribution and last, but not least, ensured that the requirements are met.

However, the results clearly outline the need for further development and calibration of the used system so that it can provide the optimal level of support for the execution of standard work processes related to the building design.

The experience from the study shows that the deploying of the full potential of VRand BIM-based solutions require iterative evaluations of both functionality and effects on the processes, so that the actual value of the technology and its abilities is utilized. 


\section{REFERENCES}

Abdelhameed, W.A. (2014). Creativity and VR use. Proceedings of the 19th International Conference on Computer-Aided Architectural Design Research in Asia, pp. 719-728.

Angulo, A. (2013). On the design of architectural spatial experiences using immersive simulation. EAEA-11 Conference Proceedings, Envisioning Architecture: Design, Evaluation, Communication, pp. 151-158.

Aydin, S. and Schnabel, M.A. (2014). A survey on the visual communication skills of BIM tools. Proceedings of the 19th International Conference on Computer-Aided Architectural Design Research in Asia, pp. 337-346.

Bullinger, H.J., Bauer, W., Wenzel, G. and Blach, R. (2010). Towards user centred design (UCD) in architecture based on immersive virtual environments. Computers in Industry Vol. 61, pp. 372-379.

Christiansson, P., Svidt, K., Pedersen, K.B. and Dybro, U. (2011). User participation in the building process. ITcon Vol. 16, pp. 309-334.

Davies, R. (2004). Adapting Virtual Reality for the Participatory Design of Work Environments. Computer Supported Cooperative Work, (13), pp. 1-33.

Dorta, T., Kinayoglu, G. and Hoffmann, M. (2016). Hyve-3D and the 3D Cursor: Architectural co-design with freedom in Virtual Reality. International Journal of Architectural Computing, 14(2), pp. 87-102.

Edwards, G., Li, H. and Wang, B. (2015). BIM based collaborative and interactive design process using computer game engine for general end-users. Visualization in Engineering, 3(4).

Eriksson, J., Glad, W. and Johansson, M. (2014). User involvement in Swedish residential building projects: a stakeholder perspective. Journal of Housing and the Built Environment, 30(2), pp. 313-329.

Goulding, J. S., Rahimian, F. P. and Wang, X. (2014). Virtual reality-based cloud BIM platform for integrated AEC projects. Journal of Information Technology in Construction (ITcon), Årgang 19, pp. 308-325.

Han, T. and Seo, Y.H. (2013). Mixed Reality System for Virtual Interior Design. International Journal of Smart Home, 7(3)

Heilig, M.L. (1962). Sensorama Simulator. United States Patent Office. 3050870

Heydarian, A., Carneiro, J.P., Gerber, D. and Becerik-Gerber, B. (2015). Immersive Virtual Environments, Understanding the Impact of Design Features and Occupant Choice upon Lighting for Building Performance. Building and Environment, Vol. 89, pp. 217228.

Hilfert, T. and Koenig, M. (2016). Low-cost virtual reality environment for engineering and construction. Visualization in engineering, 4(2).

Hsu, P.H. (2015). Architectural Visualization and communication through mobile Augmented Reality. Proceedings of the 20th International Conference of the Association for Computer-Aided Architectural Design Research in Asia, pp. 283-292.

Kim, T.W., Cha, S.H. and Kim, Y. (2015). A framework for evaluating user involvement methods in architectural, engineering, and construction projects. Architectural Science Review Vol. 59(2), pp. 136-147.

Kim, M.J., Wang, X., Love, P.E.D., Li, H. and Kang, S.C. (2013). Virtual reality for the built environment: A critical review of recent advances. Journal of Information technology in Construction, (18), pp. 279-305. 
Liu, Y., Lather, J. and Messner, J. (2014). Virtual Reality to Support the Integrated Design Process: A retrofit Case Study. International Conference on Computing in Civil and Building Engineering.

Mifflin, H. (2001). The American Heritage Dictionary. s.l.:Dell Publishing Company.

Niu, S., Pan, W. and Zhao, Y. (2015). A Virtual Reality Supported Approach to Occupancy Engagement in Building Energy Design for Closing the Energy Performance Gap. International Conference on Sustainable Design, pp. 573-580.

Oksman, V., Siltanen, S. and Ainasoja, M. (2012). User participation in co-cretive services: Developing virtual and augmented reality tools for do-it-yourself home design. Proceedings of the 16th International Academic MindTrek Conference 2012.

Porkka, J., Jung, N., Suwal, S. and Savisalo, A. (2012). Increased interaction with multiuser virtual reality in construction projects. s.l., CONVR.

Portman, M.E., Natapov, A. and Fisher-Gewirtzman, D. (2015). To go where no man has gone before: Virtual Reality in architecture, landscape architecture and environmental planning. Computers, Environment and Urban Systems, Vol.54, pp. 376-384.

Schulze, J., Hughes, C.E., Zhang, L., Edelstein, E. and Macagno, E. (2014). CaveCAD: A tool for Architectural Design in Immersive Virtual Environments. Proc. SPIE 9012, The Engineering Reality of Virtual Reality 2014

Selin, J. and Rossi, M. (2016). A survey of Universal Design by a Functional Design Method and by Gamification of Building Information Modelling. Proceedings of the 2016 Federated Conference on Computer Science and Information Systems, pp. 1671- 1674.

Siltanen, S. and Oksman, V. (2013). User-centered design of augmented reality interior design service. International Journal of Arts and sciences, 6(1), pp. 547-563.

Svidt, K. and Sørensen, J. B. (2016). Development of a Virtual Reality Solution for End User Involvement in Interior Design. Oulu, eCAADe.

Tang, J.K.T., Lau, W.M., Chan, K.K. and To, K.H. (2014). AR interior designer: Automatic furniture arrangement using spatial and functional relationships. Proceedings of the 2014 International Conference on Virtual Systems and Multimedia, pp.345-352.

Thabet, W., M.F. Shiratuddin and Bowman, D. (2002). Virtual Reality in Construction: A Review. I: Engineering Computational Technology, pp. 25-52.

Tutt, D. and Harty, C. (2013). Journeys through the CAVE: the use of 3D immersive environments for client engagement practices in hospital design. Procs 29th Annual ARCOM Conference, pp. 111-121.

Vorländer, M., Schröder, D., Pelzer, S. and Wefers, F. (2015). Virtual reality for architectural acoustics. Journal of Building Performance Simlation, 8(1), pp. 15-25.

Wahlström, M., Aittala, M. and Kotilainen, H. (2010). CAVE for collaborative patient room design: analysis with end-user opinion contrasting method. Virtual Reality, Vol.14, pp. 197-211.

Wang, J., Wang, X., Shou, W. and Xu, B. (2014). Integrating BIM and augmented reality for interactive architectural visualisation", Construction Innovation, 14 (4), pp. 453476.

Zhou, S.Z. and Guo, J. (2013). Interior Design Framework Integrating Mixed Reality with the Multi-touch Tabletop Interface and its Extension for Collocated and Remote collaboration. International Journal of Computer Science and Application, 2(1). 